\title{
Flexibility in Sustainable Electricity Systems: Multivector and Multisector Nexus Perspectives
}

DOI:

10.1109/MELE.2019.2908890

\section{Document Version}

Accepted author manuscript

Link to publication record in Manchester Research Explorer

\section{Citation for published version (APA):}

Martinez Cesena, E. A., Good, N., Panteli, M., Mutale, J., \& Mancarella, P. (2019). Flexibility in Sustainable Electricity Systems: Multivector and Multisector Nexus Perspectives. IEEE Electrification Magazine, 7(2), 12-21. https://doi.org/10.1109/MELE.2019.2908890

\section{Published in:}

IEEE Electrification Magazine

\section{Citing this paper}

Please note that where the full-text provided on Manchester Research Explorer is the Author Accepted Manuscript or Proof version this may differ from the final Published version. If citing, it is advised that you check and use the publisher's definitive version.

\section{General rights}

Copyright and moral rights for the publications made accessible in the Research Explorer are retained by the authors and/or other copyright owners and it is a condition of accessing publications that users recognise and abide by the legal requirements associated with these rights.

\section{Takedown policy}

If you believe that this document breaches copyright please refer to the University of Manchester's Takedown Procedures [http://man.ac.uk/04Y6Bo] or contact uml.scholarlycommunications@manchester.ac.uk providing relevant details, so we can investigate your claim.

\section{OPEN ACCESS}




\section{Flexibility in Sustainable Electricity Systems: Multi-vector and Multi-sector Nexus Perspectives}

By E. A. Martínez Ceseña, N. Good, M. Panteli, J. Mutale and P. Mancarella

Due to increasing environmental concerns, there is growing interest amongst researchers, policy makers, and the public in general in better options to make energy more sustainable and, at the same time, ensuring that energy systems are affordable, reliable and resilient. This is bringing about different grand challenges across the world as established energy systems (e.g., in cities) must be enhanced to integrate large volumes of Renewable Energy Sources (RES), while new or evolving systems (e.g., in developing economies) must be planned to cope with increasingly extreme conditions associated with climate change. In these contexts, the flexibility to intelligently use and invest in resources that go beyond the power system (e.g., other energy vectors such as heat or gas and assets such as water dams) can be extremely valuable from a sustainable development perspective.

In cities, energy decarbonisation and sustainable development are encouraging the electrification of transports, heating and other services, as well as the large scale integration of RES. Taking the UK as an example, with the aim of decarbonising transports by 2040, all sales of new petrol and diesel cars will be banned by 2032 . Also, as heating corresponds to $40 \%$ of domestic energy demand in the UK, the government offers a 7 year domestic renewable heat incentive for customers who install Electric Heat Pumps (EHPs) or other forms of renewable heating. At first glance, these solutions seem highly attractive because electricity can be easily decarbonised if it is produced with RES which are becoming progressively cheaper. However, accommodating the new demand and RES generation in the electricity system is not an easy task. Massive investments would be required in electricity grid infrastructure (e.g., lines and substations) to accommodate the new power flows, as well as in generation, storage and other technologies that can provide reserve and active control to balance the highly intermittent output of some RES such as wind and solar Photovoltaic (PV). A more effective approach would be to take advantage of the already existing assets (including district heating and gas networks) and ongoing advances in information and communication technologies (ICT) and automation to enable demand side flexibility, much of which is enabled by multi-energy technologies. This multi-vector approach to demand side flexibility empowers customers to use combinations of energy vectors (e.g., electricity, heat and gas) to better meet their energy needs, while also providing valuable capacity and reserve support to the energy system.

The multi-vector vision of energy flexibility recognises the attractiveness of using a suite of energy vectors and networks to meet customer needs. Taking this vision a step further, it may not make sense to constrain flexibility to the energy sector in areas where little or no energy infrastructure has been installed, such as in rural areas or developing economies. Instead, it is more valuable and sensible to consider the flexibility that investments in some infrastructure can offer to different sectors, such as hydropower plants which couple the energy and water sectors and allow flexibility to be deployed to the benefit of other sectors (e.g., releasing water from the energy sector to be used in the agricultural sector). The flexible use of different resources provides new opportunities to more efficiently bring lighting, water, food and other valuable services to underserved customers. However, in the so-called water-energy nexus, this increased flexibility needs to be properly 
balanced within the context of potential competition arising between services, e.g., trade-offs arise when it has to be decided whether to use water for electricity generation or irrigation.

The smart and strategic use of flexibility from the demand side and different energy technologies (e.g., from distributed devices such as EHPs to large technologies such as hydropower plants) will be critical for sustainable development based on both novel multi-vector and waterenergy nexus perspectives. This work illustrates, with examples on a smart district and an integrated energywater system, sophisticated applications of flexibility that to go beyond the power system, also taking advantage of coupling with other energy vectors and sectors.

\section{A flexible energy future}

\subsection{Different energy futures}

Figures 1 to 4 present different options for the development of an energy system that supplies a district with electricity and heat. In a traditionally decoupled case (see Figure 1), dedicated systems supply customers with different energy vectors such as electricity and heat. This configuration has the advantage of allowing the independent operation of each network and market, without explicit consideration of other systems. However, in this example, the demand side has limited capability to support the system, as customers would have to change their behavior or be curtailed (incurring discomfort) to reduce their energy demand.

The electricity centered approach to integrate intermittent RES in the electricity sector and electrify other energy vectors (e.g., heat) is illustrated in Figure 2. The approach has the advantage of allowing the use of more RES generation to produce heat. However, heat demand and RES generation may be poorly correlated, as is the case in the UK where the maximum heat demand can be expected during winter when PV generation is low. Once again, there is little flexibility for the demand side to provide system support.

Some of these issues can be tackled with the installation of energy storage (e.g., batteries and thermal energy storage (TES)). Surplus PV generation can then be stored by the battery for later use or, as shown in Figure 3 , converted to heat and stored for later use. This strategy could reduce electricity demand as the heat stored in the TES could reduce EHP operation at later times. This system is more flexible than those presented before as the now multienergy system allows the intelligent use of TES (through

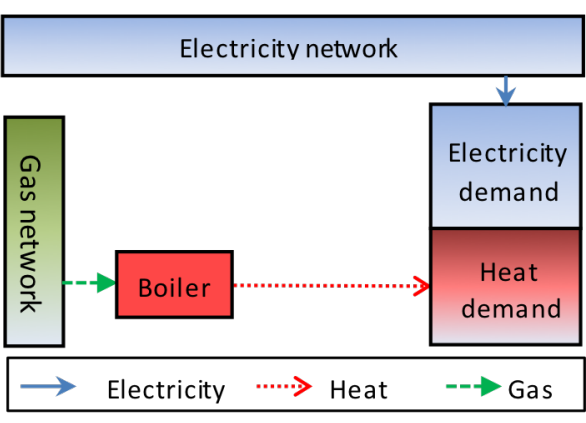

Figure1: Traditionally decoupled energy services.

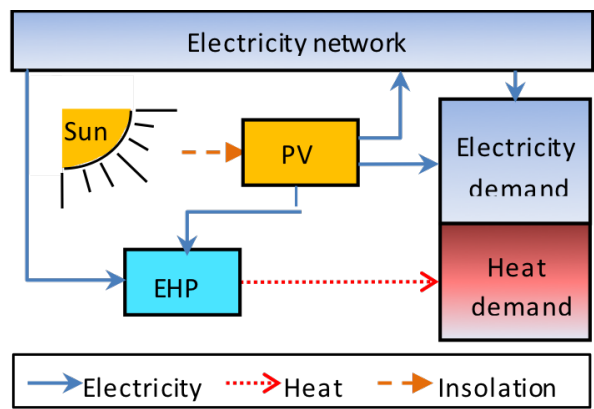

Figure2: Electrifying heat.

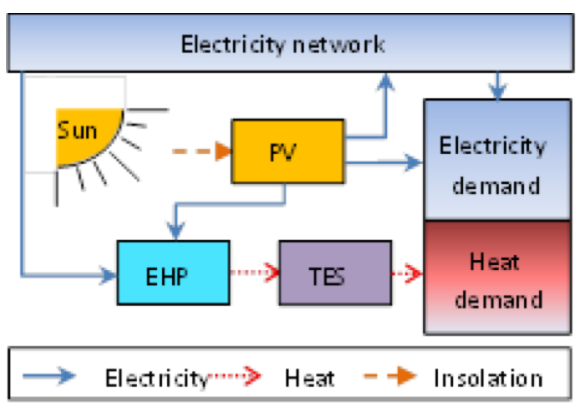

Figure3: Electrifying heat and installing TES.

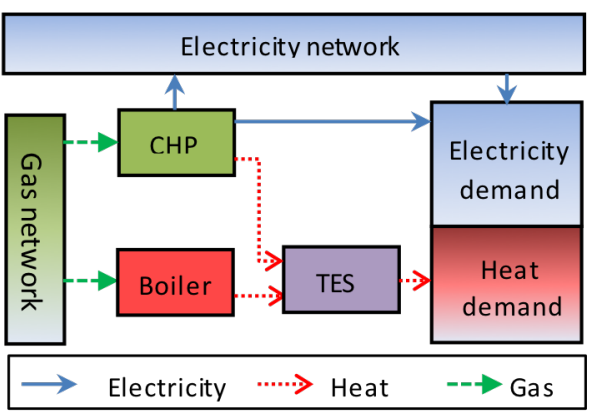

Figure4: Installing CHP and TES. the use of ICT and automation) to control electricity imports and exports without affecting 
customers. For example, electricity imports can be reduced by ramping down the EHP while still meeting customer needs with the TES. The downside of this approach is that it does not take advantage of available infrastructure, such as the gas network and boiler shown in Figure 1.

Other options, such as the one presented in Figure 4, involve the installation of various low carbon multi-energy technologies such as Combined Heat and Power (CHP) boilers and TES; other technologies such as PV and EHP can also be added. This type of system is highly flexible as there are multiple controllable options to meet electricity and heat demand. For example, if grid electricity is cheap and clean due to the availability of RES, electricity imports can be increased by ramping down the CHP boiler and meeting heat demand with the TES and boiler. It is also possible to reduce grid imports (e.g., to provide active network management) by ramping up the CHP boiler and storing surplus heat with the TES. This provides customers with new options to not only meet their energy needs, but to also reduce their energy bills, minimize their carbon emissions or pursue other objectives.

\subsection{Integrated multi-energy systems}

It should be expected that the different energy futures presented in Figure 1 to Figure 4 would lead to various coupling of energy vectors. This coupling can impact the networks that may be in place to supply each vector, such as the electricity, gas and, where applicable, district heating networks. Understanding these complex effects is not trivial, but is necessary as large scale electrification of heating and transports can lead to significant electricity network stress. Furthermore, in a multienergy future, actively managing stress in one network can lead to issues in others, e.g., the use of CHP boilers to provide electricity network support may cause issues in the heat and gas networks. To visualize the effects, it is convenient to map how different energy vectors are converted to useful services or energy vectors (e.g., using generators and other conversion technologies) and how energy vectors are distributed to customers using the available networks.

To illustrate this, consider the Manchester district in the UK presented in Figure 5. The district comprises 26 buildings owned by The University of Manchester, some of which are connected to the same electricity distribution network $(6.6 \mathrm{kV})$, district heating network and gas network. The district has an annual demand of $28 \mathrm{GWh}$ ( $6 \mathrm{MW}$ peak) of electricity and $18 \mathrm{GWh}$ (12 MW peak) of heat. The current, baseline, annual energy costs and carbon emissions are $3.1 \mathrm{fM}$ and $19.1 \mathrm{ktCO}_{2}$. Different options for meeting the electricity and heat needs of the district are mapped using Sankey diagrams in Figure 6, Figure 7 and Figure 8. The district, and various options to make it more flexible were investigated in the "District Information Modelling and Management for Energy Reduction" (DIMMER) research project.

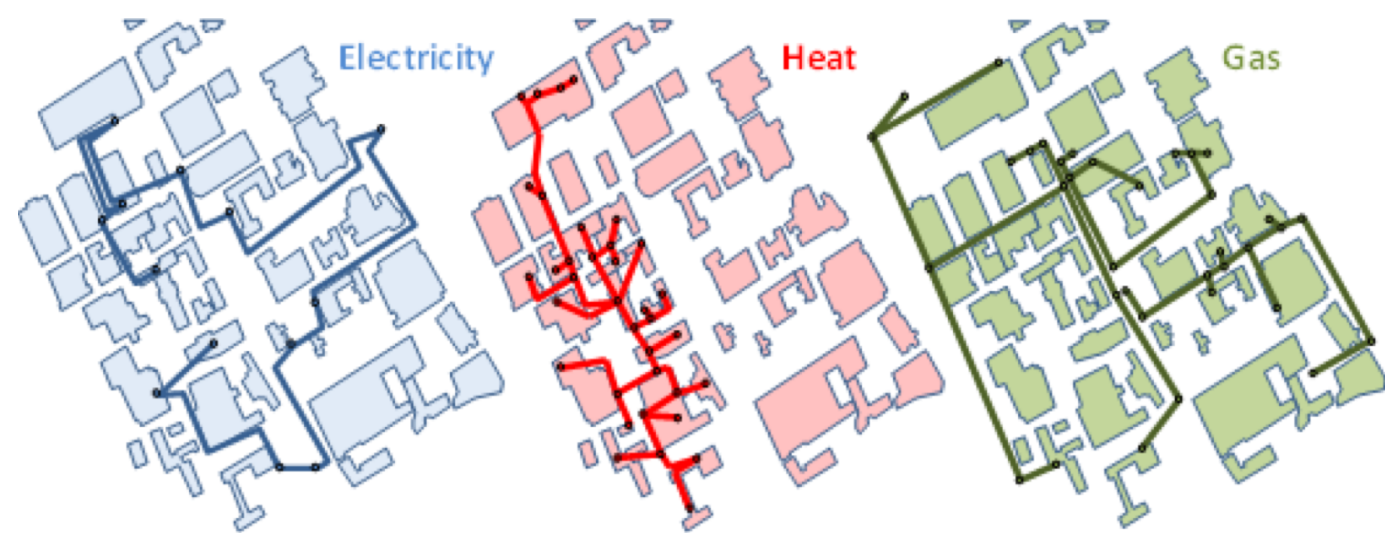

Figure 5: Manchester multi-energy district. 


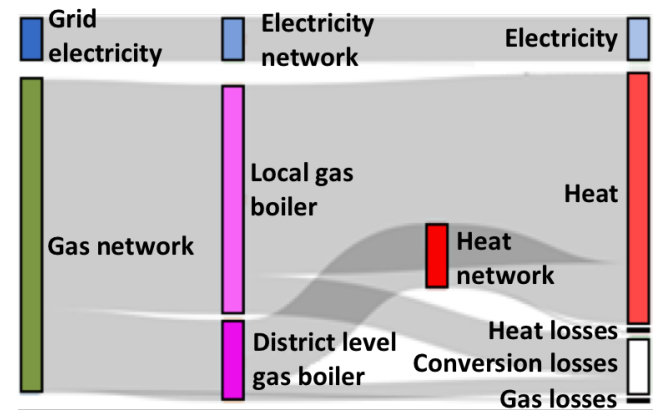

Figure 6: Sankey diagram - Decoupled energy

Figure 7: Sankey diagram - Multi-energy svstem.

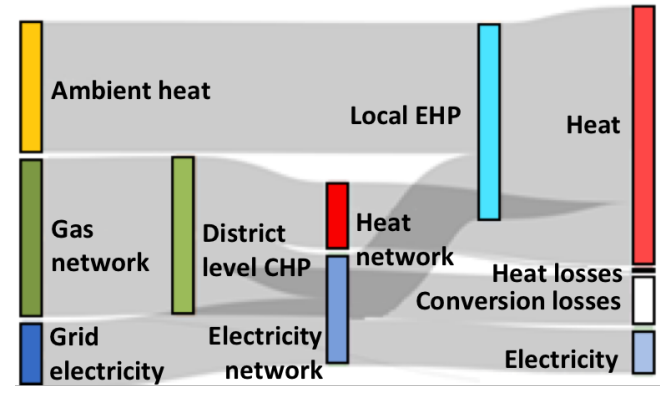

Figure 8: Sankey diagram - Electrifying heat. services

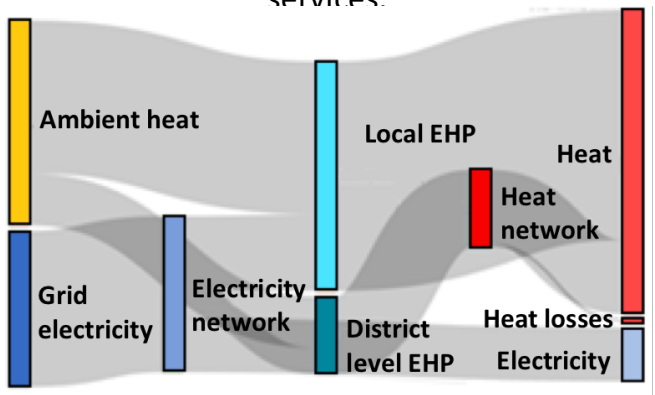

The traditionally decoupled energy system depicted in Figure 6 is taken as a Baseline to represent current conditions. In this case, electricity is delivered to customers using the electricity networks, whereas heat is produced with local boilers, or larger boilers connected to a district heating network, which take fuel from the gas network. In the electrified future presented in Figure 7, the gas network is no longer used and, instead, significantly more electricity is taken from the grid (compared with the Baseline in Figure 6) to supply EHPs. The electricity grid would require additional capacity to reliably meet the new demand. In this context, the reliability of the electricity system becomes more critical as outages would impact both electricity and heat supply, which can make customers more vulnerable especially during periods with harsh ambient conditions e.g., in the UK, energy system stress and the impacts of contingencies on the network and customers are the highest during the coldest winter days.

In the multi-energy future presented in Figure 8, the electricity grid, local EHPs and district CHP boilers are used to meet customer needs. Additional demand on the electricity grid is modest compared with the case presented in Figure 7, and the system still utilizes some capacity of the gas network. In this case, additional future demand growth can still be met with low carbon technologies (e.g., CHP boilers), which may not require network reinforcements. The system is also more flexible to withstand contingencies in the electricity or gas networks, i.e., if the electricity supply is interrupted, local heat and electricity can be produced with the CHP boilers, whereas the EHPs can be used to supply some customers if the supply of gas is interrupted.

The multi-energy futures offer greater flexibility and use of existing assets, and lower network stress than the electrified future. However, this energy future is also the most complex as the traditionally decoupled energy systems (e.g., electricity, heat and gas) would operate as a single integrated system. As a result, the energy sector will no longer comprise independent systems that provide electricity, heat, gas and other energy vectors. Instead, the energy system will comprise integrated assets that flexibly use combinations of multiple available energy vectors to meet customers' needs for lighting, heating, cooking and other services.

Even though the abovementioned examples (From Figure 1 to Figure 8) are for multi-vector applications of flexibility in smart cities, it is possible to infer some key ideas that are applicable to the energy nexus in rural areas and developing economies. Firstly, more and potentially better options to meet customer needs become available when considering the coupling of multiple sectors (energy vectors in the examples). Flexibility makes the system more resilient to extreme events caused by climate change (network contingencies in the examples). New trade-offs can arise as a limited resource are used to provide different resources, e.g., water can be used for electricity generation or irrigation (demand response could be used to reduce energy bills or carbon emissions in the examples). 


\section{The value of multi-vector flexibility}

\subsection{Investing in multi-energy assets}

To illustrate the value of flexibility that can be attributed to multi-energy assets, consider the Manchester district under traditionally decoupled Baseline conditions and Business as Usual (BAU) operation (i.e., heat following mode). In addition to the Baseline case, which represents the current conditions of the system, three different cases are considered, namely Conservative, Modest and Extreme cases. In the Conservative case, in addition to installing PV, EHP and CHP devices, the University invests in awareness campaigns to encourage switching lights and computers off when not in use, and modest interventions in double glazed steel windows and waterproof roof covers. In the Modest case, additional investments in energy devices and efficiency measures throughout the university are made. In the extreme case, relatively large investments in energy efficiency measures are made, coupled with significant installation of energy infrastructure. The total installed PV, EHP and CHP capacities associated with each case are presented in Table 1 and the relevant economic and environmental performance of the district is presented in Table 2.

Table 1: Installed boiler, PV, EHP and CHP capacities in each case.

\begin{tabular}{|c|c|c|c|c|}
\hline \multirow[t]{2}{*}{ Case } & \multicolumn{4}{|c|}{ Aggregated installed capacity throughout the district (kW) } \\
\hline & Boiler & PV & EHP & CHP \\
\hline Baseline & 24000 & 93 & 0 & 0 \\
\hline Conservative & 24000 & 1068 & 310 & 260 \\
\hline Modest & 24000 & 2250 & 1715 & 1925 \\
\hline Extreme & 24000 & 3410 & 2650 & 2700 \\
\hline
\end{tabular}

Table 2: Performance of the Manchester district subject to the considered cases and BAU practices.

\begin{tabular}{|c|c|c|c|c|}
\hline & Baseline & Conservative & Modest & Extreme \\
\hline Annual economic savings* & $0 \%$ & $9.06 \%$ & $12.22 \%$ & $14.83 \%$ \\
\hline Annual carbon savings* & $0 \%$ & $10.14 \%$ & $19.94 \%$ & $26.90 \%$ \\
\hline Peak Electrical Demand Reduction* & $0 \%$ & $4.67 \%$ & $2.20 \%$ & $2.37 \%$ \\
\hline Peak Heat Demand Reduction* & $0 \%$ & $15.50 \%$ & $52.80 \%$ & $72.51 \%$ \\
\hline
\end{tabular}

*Compared with the baseline

In these cases, following BAU practices, the multi-energy infrastructure is operated in heat-following mode. These practices do not take advantage of the variable needs of the energy sector or the potential for the district to operate in a smart manner. Accordingly, it is reasonable to assume that the benefits reported in Table 2 correspond mainly to the value of flexibility introduced by multienergy assets.

\subsection{Smarter operation}

By optimizing the set points of the controllable devices within the district, it is possible to pursue different objectives such as economic and carbon savings. This smart operation (whereby the district is operated taking into account variable price signals, which reflect the costs of the energy supply, network/system operation and taxes), allows customers to minimize their energy bills and carbon emissions, and could also allow customers to trade demand side flexibility in different markets. This smart operation can be substantially more attractive than traditional BAU practices as illustrated in Table 3. The study shows that the smart operation of the district can improve the performance of the district, especially in the more extreme cases where more controllable resources are available.

Table 3: Performance of the Manchester district subject to the considered cases - BAU vs smart practices

\begin{tabular}{|c|c|c|c|c|c|c|}
\hline & $\begin{array}{l}\text { Conserv } \\
\text { (BAU) }\end{array}$ & $\begin{array}{l}\text { e } \\
\text { (smart) }\end{array}$ & $\begin{array}{l}\text { Modest } \\
\text { (BAU) }\end{array}$ & (smart) & $\begin{array}{l}\text { Extreme } \\
\text { (BAU) }\end{array}$ & (smart) \\
\hline Annual economic savings* & $9.06 \%$ & $9.54 \%$ & $12.22 \%$ & $21.44 \%$ & $14.83 \%$ & $28.43 \%$ \\
\hline Annual carbon savings* & $10.14 \%$ & $10.28 \%$ & $19.94 \%$ & $27.00 \%$ & $26.90 \%$ & $38.07 \%$ \\
\hline Peak Heat Demand Reduction* & $4.67 \%$ & $12.63 \%$ & $2.20 \%$ & $41.03 \%$ & $2.37 \%$ & $49.38 \%$ \\
\hline Peak Electrical Demand Reduction* & $15.50 \%$ & $28.48 \%$ & $52.80 \%$ & $84.88 \%$ & $72.51 \%$ & $95.07 \%$ \\
\hline
\end{tabular}

*Compared with the baseline 
The study is taken one step further by optimizing the operation of the district based on a wide range of different objectives, including minimization of costs and emissions, and maximization of benefits from the trade of active network management, energy, reserve and other services in relevant markets (see suite of results in terms of the Net Present Cost - NPC - in Figure 9). This smart operation of the district is more in line with the premise that the energy system should not be operated to provide energy vectors (e.g., electricity and gas), but instead use combinations of available energy vectors to meet customers' needs such as lighting, heating, and other services. The results show that, by customizing the operation of the district, it is possible to achieve different environmental and economic savings. This is particularly valuable in an uncertain future where RES generation, asset costs or other assumed parameters are different than forecasted. For example, carbon targets can still be met by changing the operation of the Manchester district (without investing in additional assets) even if the future differs from the forecast.

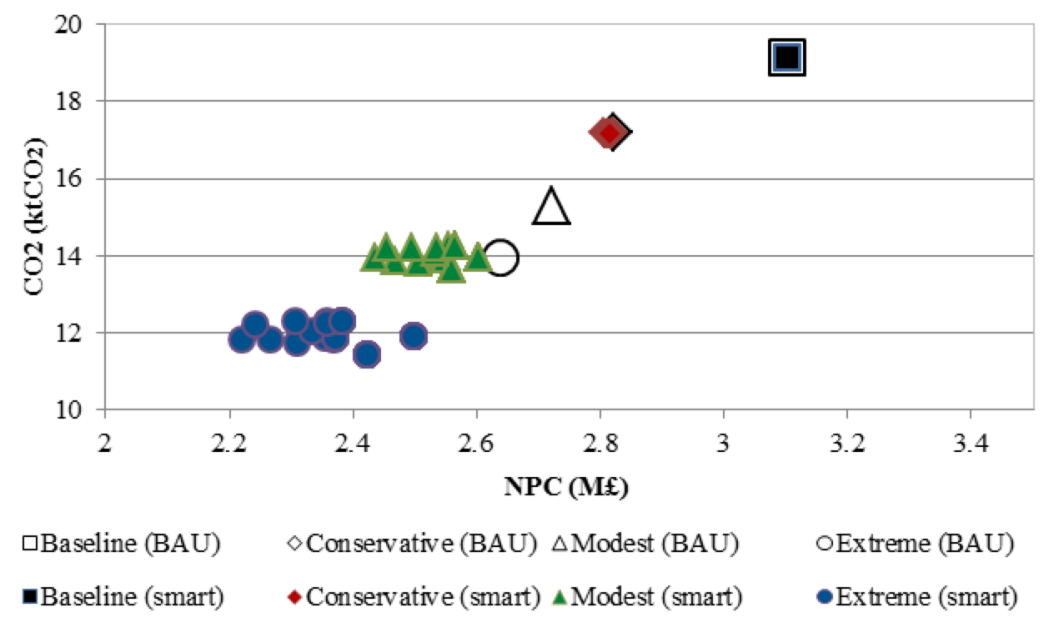

Figure 9: Performance of the Manchester district under different conditions.

It is important to highlight that the flexibility provided by smart operation can be as valuable as, or more valuable than, the one provided by the asset. This can be deduced by comparing the Extreme (BAU) and Conservative (smart) cases in Figure 9. The latter, which utilizes fewer assets, can outperform the former, which does not take advantage of smart operation. This is further demonstrated in Table 4, which takes the maximum and minimum values from Figure 9. The table shows that most of benefits in the extreme case can be attributed to the smart operation of the assets. This is an important result because it demonstrates that it is not enough to foresee a sustainable multi-vector future by installing RES and multi-energy technologies; most of the value offered by these technologies will only materialize if the assets are also smartly operated.

Table 4: Value of flexibility associated with assets and smart operation.

\begin{tabular}{|c|c|c|c|c|c|c|}
\hline \multirow[t]{3}{*}{ Benefit attributed to } & \multicolumn{6}{|c|}{ Economic savings (\%*) } \\
\hline & \multicolumn{2}{|c|}{ Conservative } & \multicolumn{2}{|c|}{ Modest } & \multicolumn{2}{|c|}{ Extreme } \\
\hline & Min & $\operatorname{Max}$ & Min & $\operatorname{Max}$ & Min & Max \\
\hline Assets & 10.17 & 9.06 & 20.02 & 12.22 & 27.06 & 14.83 \\
\hline Smart operation & 0.31 & 0.47 & 8.61 & 9.98 & 13.1 & 15.33 \\
\hline Total & 10.48 & 9.54 & 28.63 & 22.20 & 40.16 & 30.16 \\
\hline
\end{tabular}




\section{Beyond the demand side}

\subsection{Impacts on the energy system}

As flexibility increases in the energy sector, mostly due to the introduction of multi-energy technologies at the demand side, smart community multi-energy systems (e.g., the Manchester district) will take some of the business away from current actors. That is, a significant volume of energy may be generated and consumed locally, instead of produced by large generators and transported by the Transmission System Operator (TSO) and multiple Distribution Network Operators (DNOs). This new system operation may be beneficial if it displaces dirty and expensive electricity generation units. But it can also be harmful if, for instance, it reduces the revenue to network operators, who are responsible for connecting the multi-energy resources and enabling the business of smart districts, can collect, or it makes the business case for new firm generation too risky.

To understand the impacts that demand side flexibility (e.g., from the Manchester district) can have on the energy sector, it is convenient to map the interactions within the energy sector (see Figure10). The map, developed using value-flow mapping approaches, tracks the energy, cash and information exchanges between different actors in the energy sector. These exchanges are based on (i) the physical characteristics of the system, e.g., electricity is generated by producers and travels through the transmission and distribution networks to reach customers; (ii) regulatory framework, e.g., customers pay retailers who then pay DNOs, the TSO and other actors; and (iii) emerging business cases, e.g., contractors may provide operation and maintenance to the multi energy infrastructure within the smart district.

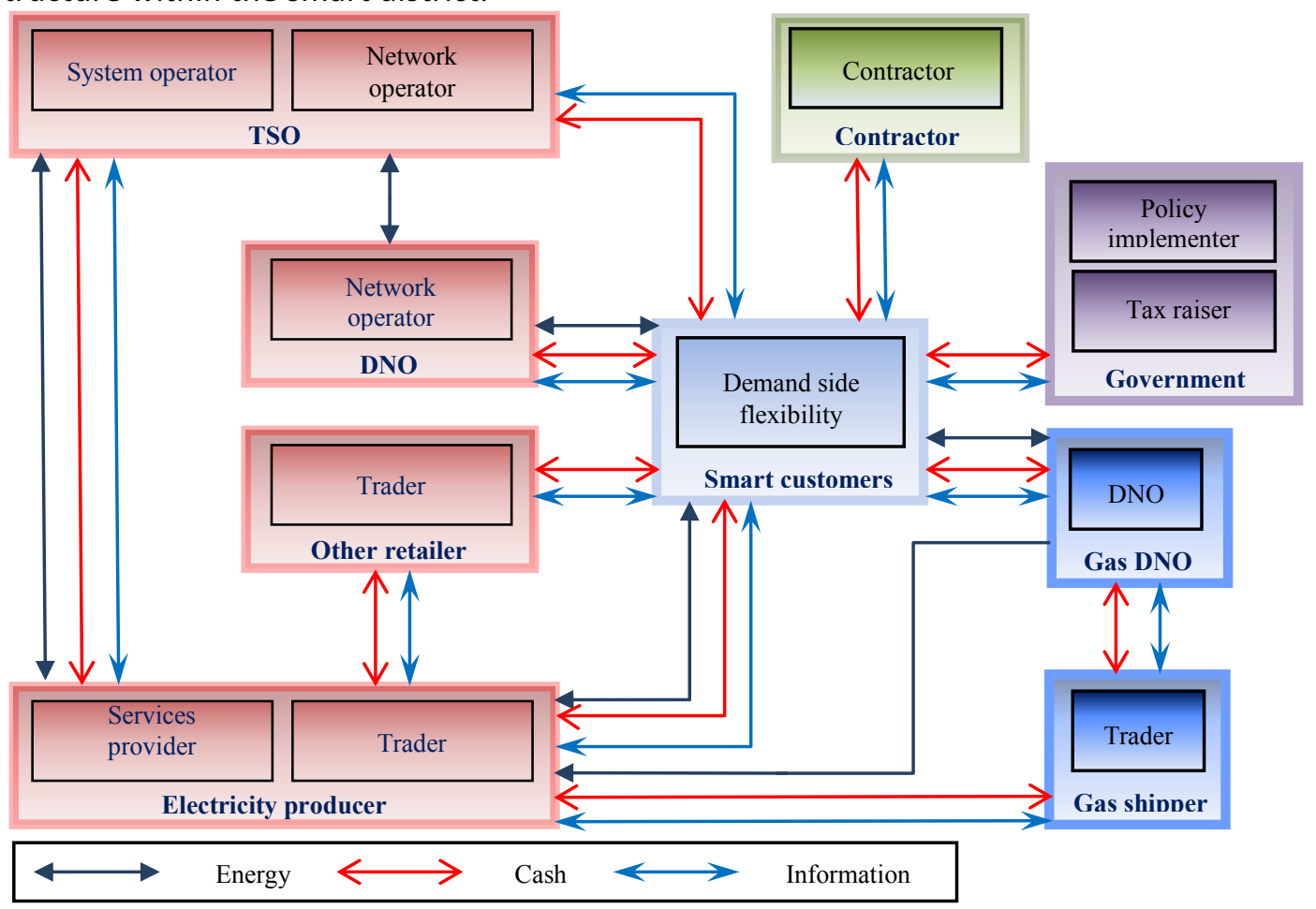

Figure 10: Value flow map.

One of the key advantages of the value flow mapping approach is that it facilitates quantifying the effects of district optimization on different revenue flows, for customers within the district and other actors (see Figure 11 for quantification of the change of revenue for selected actors). In this context, district manager, retailer, aggregators or other actors that can represent customers in different energy markets no longer focus only on the provision of energy vectors but, instead, on providing 


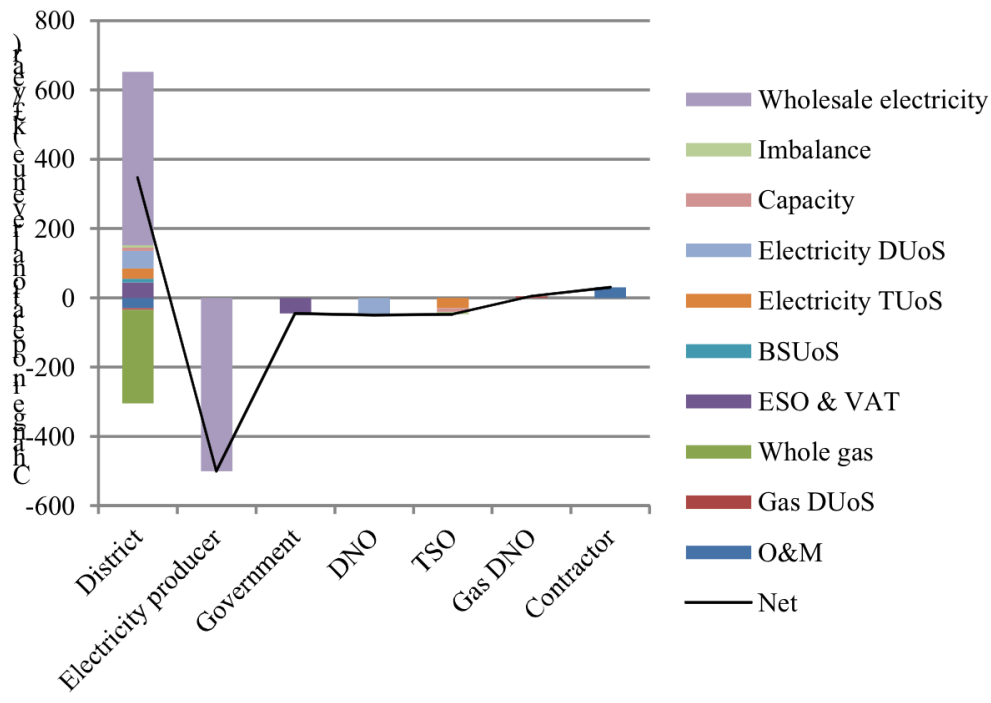

Figure 11: Business case analysis. services. These services can be tracked to the actors who would normally provide them, so that the impact of the smart district on the business of such actors can be assessed. In this example, the smart operation of the Manchester district in the extreme case brings about significant benefits to customers by taking advantage of price arbitrage in the wholesale energy market and reducing network charges and payment of taxes. This would have a negative impact in the form of loss of revenue

(compared with BAU case) for electricity producers, the government and network operators, i.e., reduction in distribution and transmission Use of System charges (DUoS and TUoS). As discussed above, some of these effects can be deemed acceptable if, for example, carbon intensive generators are driven out of business. However, the reduction in revenue collected for network operators may not be acceptable, especially when considering that the integration of the different distributed multi-energy technologies within the district may lead to increased network stress and costs.

This information is critical to understand potential issues for the introduction of demand side flexibility from the perspective of the energy system and different actors. For example, based on the study presented in Figure 11, it may be convenient to introduce active network management services, adjust network charges, or introduce other mechanisms to allow network operators to support their business, as well as the business of the smart district.

\subsection{The energy nexus}

It has been shown that multi-vector application of energy system flexibility can be used as a means to meet customers' energy needs in cities with established energy networks. Taking a step further, a

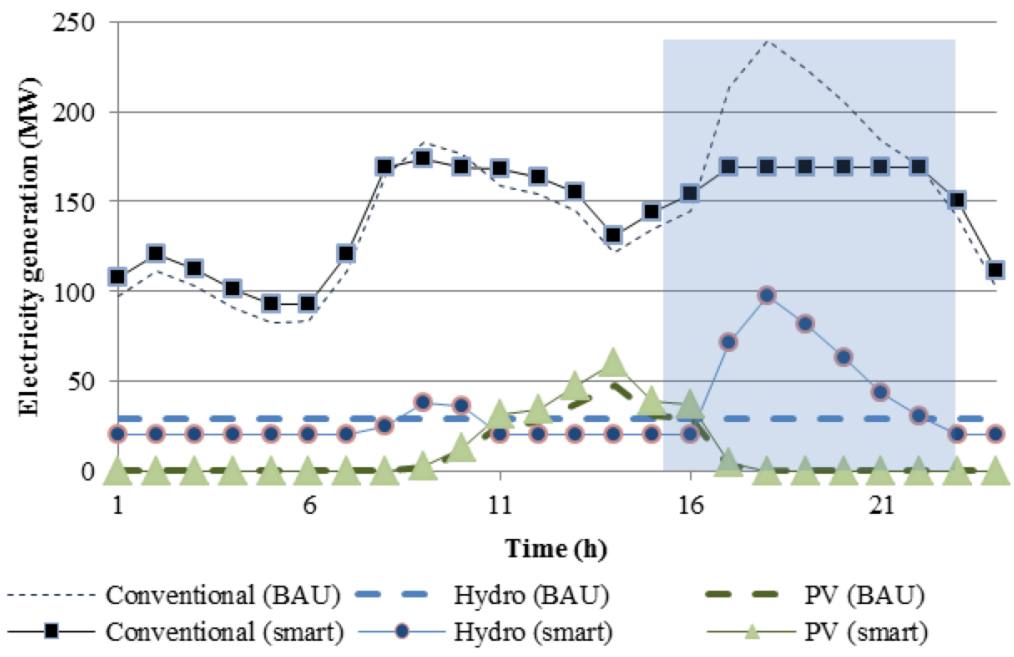

Figure 12: Conventional, hydropower and PV generation profiles subject to BAU and smart operation. multi-sector energy nexus approach is better suited for providing food, water, lighting, and other critical services for people in rural communities and developing economies. To illustrate this, consider that the flexible use of hydropower plants to balance intermittent RES (e.g., PV power), by storing surplus solar power as water. As shown in Figure 12, which is based on the IEEE 14 bus test network, the smart operation of the hydropower plant can greatly reduce the peak conventional generation capacity required by the 
system and increase the production of clean power. In this example, peak conventional generation and total PV generation in the smart cases are respectively $15 \%$ lower and $20 \%$ higher than in the BAU case.

This increased flexibility of the power system can be used to bring attractive benefits to the energy sector by reducing electricity costs and carbon emissions, and displacing conventional peaking generation. That is, the flexibility would allow the system to meet customers' needs for affordable and sustainable electricity. However, the added flexibility of the system could be used instead to maintain the affordability and sustainability of the current energy services while reducing the use of hydropower. The result would be: reduced future investments in hydropower capacity, a lower water demand for the generation of electricity, and more water available for irrigation, drinking, and other uses; also potentially

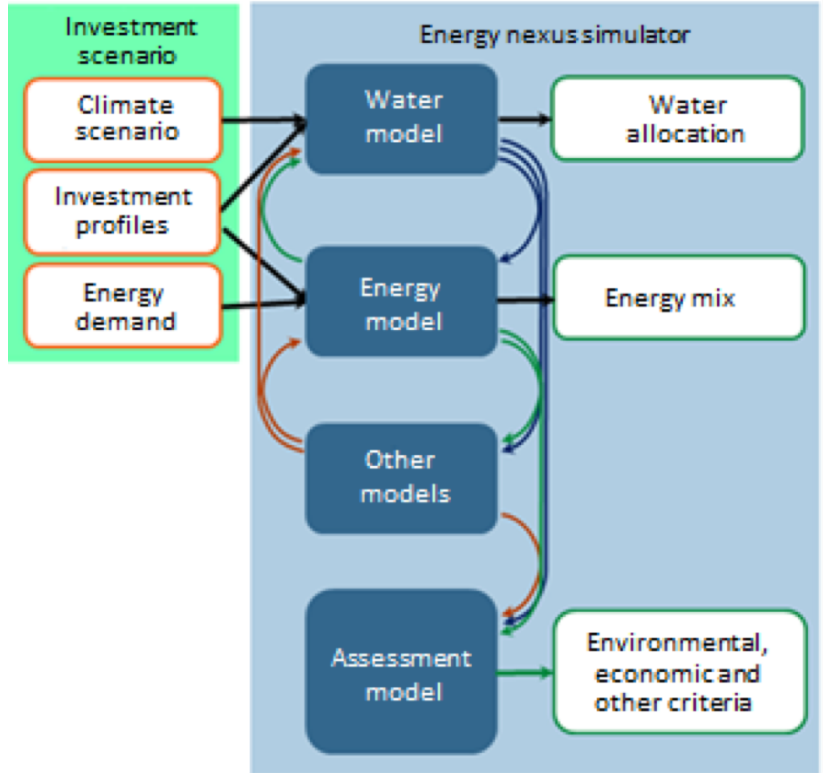

Figure 13: Energy nexus planning and assessment framework. avoiding the construction of costly and carbon intensive infrastructure in different sectors.

Based on such water-energy nexus vision, the energy system is treated as part of a wider suite of interrelated sectors. In this context flexibility is no longer constrained to the use of energy vectors to meet customers' needs but also to optimize the use of water, food, and other resources. In order to investigate this advanced use of flexibility, novel frameworks, such as the one presented in Figure 13 , have been proposed to assess interactions between different sectors and shed light on the smart use of flexibility and deployment of infrastructure that would be the most beneficial for different sectors subject to an uncertain future.

"Nexus tools" can, for instance, bring together specialized models of different sectors in an iterative fashion to produce a wide range of strategies to invest in electrification, multi-energy technologies, and other infrastructures required to meet customers' needs. The tools are particularly attractive to tackle highly uncertain scenarios where the use of flexibility (from different energy vectors and various sectors) is critical, such as for developing future energy-water-food systems that are resilient to climate change.

Even with the sophisticated energy nexus tools, the identified strategies are seldom perfect and will have several positive and negative impacts in different sectors (i.e., trade-offs). Assessing the tradeoffs between different sectors is not an easy task (e.g., comparing the value of minimizing the risks of a power outage against the risks of a flood) and will require lengthy negotiations between planners, policy makers and relevant actors in each sector. Regardless, the identified strategies could be generally significantly better than those identified by addressing a single sector.

\section{Conclusion}

The sustainable development goals set by the United Nations are more and more motivating the flexible use of different resources from various vectors and sectors to meet customer needs. A multivector approach to demand side flexibility will be particularly valuable in cities that already have 
significant energy infrastructure. In these cases, the integration of multi-energy technologies such as cogeneration, batteries and thermal storage which, if enabled with ICT, automation and smart control, would make the energy system significantly more flexible. The large scale deployment of these resources may lead to a new role for flexibility in the operation of the energy sector as the focus of the sector will no longer be on the provision of electricity, gas and other vectors but, instead, on the use of combinations of energy vectors for the provision of customers' services.

The services that can be provided with the smart use of flexibility do not have to be constrained to energy, particularly in rural areas or developing economies where little or no energy infrastructure is in place. Instead, a more holistic multi-sector nexus approach can be used to enable the use of flexibility to better provide energy, water, food and other key services.

Although the multi-vector and nexus approaches are more complex than the traditionally decoupled approaches for energy planning, these approaches provide attractive options to better tackle grand challenges, such as climate change and large scale integration of RES. In this context, it is critical to rethink the role of flexibility as a means to intelligently take advantage of available resources and strategic investments, and effectively provide the services required by people.

\section{Acknowledgments}

The authors would like to acknowledge the European Commission, the UK Engineering and Physical Sciences Research Council (EPSRC), and the UK Economic and Social Research Council (ESRC) for their financial support to carry out part of this work as part of the "DIMMER: District Information Modelling and Management for Energy Reductions" (FP7 609084), "MY-STORE: Multi-energY storageSocial, TechnO-economic, Regulatory and Environmental assessment under uncertainty" (EP/N001974/1), and "FutureDAMS: Design and Assessment of water-energy-food-environment Mega-Systems" (ES/P011373/1) projects, respectively.

\section{For further reading}

- E. A. Martínez Ceseña and P. Mancarella, "Energy systems integration in Smart districts: Robust optimisation of multi-energy flows in integrated electricity, heat and gas networks," IEEE Transactions on Smart Grid, Vol. 10, pp. $1122-1131,2019$.

- X. Liu, P. Mancarella, "Modelling, assessment and Sankey diagrams of integrated electricity-heatgas networks in multi-vector district energy systems," Applied Energy, Vol. 167, pp. 336 -352, 2016. - N. Good, E. A. Martínez Ceseña, C. Heltorp, and P. Mancarella, "A transactive energy modelling and assessment framework for demand response business cases in smart distributed multi-energy systems," Energy, In press, 2018.

- E. A. Martínez Ceseña, N. Good, A. L. A. Syrri, P. Mancarella, "Techno-economic and business case assessment of multi-energy microgrids with co-optimization of energy, reserve and reliability services," Applied Energy, Vol. 210, pp. 896-913, 2018.

- N. Good, E. A. Martínez Ceseña and P. Mancarella, "Ten questions concerning smart districts," Building and Environment, Vol. 116, pp. 362 -376, 2017.

- E. A. Martínez Ceseña, T. Capuder and P. Mancarella, "Flexible distributed multi-energy generation system expansion planning under uncertainty," IEEE Transactions on Smart Grid, Vol. 7, no. 1, pp. $348-357,2016$.

- N. Good, E. A. Martínez Ceseña, L. Zhang and P. Mancarella, "Techno-economic assessment and business case modelling of low carbon technologies in distributed multi-energy systems," Applied Energy, Vol. 167, pp. $158-172,2016$.

- Y. Zhou, M. Panteli, R. Moreno and P. Mancarella, "System-Level Assessment of Reliability and Resilience Provision from Microgrids", Applied Energy, Vol. 230, pp. 374 -392, 2018. 


\section{Biographies}

- E. A. Martínez Ceseña (alex.martinezcesena@manchester.ac.uk) is a Research Fellow at The University of Manchester, UK

- N. Good (nickg@upsideenergy.co.uk) is Senior Data Scientist at Upside Energy Ltd, Manchester, UK, and an honorary Research Associate at The University of Manchester, UK

- M. Panteli (mathaios.panteli@manchester.ac.uk) is a Lecturer at The University of Manchester, UK

- Joseph Mutale (j.mutale@manchester.ac.uk) is a Professor at The University of Manchester, UK

- Pierluigi Mancarella (pierluigi.mancarella@unimelb.edu.au) is a Professor at the University of Melbourne, Australia, and a part-time Professor at The University of Manchester, UK 